\title{
The antibiotic sensitivity pattern and the use of antibiotics in women with asymptomatic bacteriuria in pregnancy
}

\author{
Samarawickrama NGCL , ${ }^{a}$ Withanathantrige MR, ${ }^{b}$ Silva KCDP ${ }^{c}$
}

\begin{abstract}
Key Words: Asymptomatic bacteriuria, Pregnancy, Nitrofurantoin

Background: Nitrofurantoin has been recommended as a first line therapy in Sri Lanka for urinary tract infections in pregnancy but it is not used frequently

Materials and Methods: At the Colombo South Teaching Hospital a descriptive cross sectional study was carried out from June 2015 to April 2016 on 98 consecutive pregnant women between eight to 24 weeks of gestation, residing in Colombo district and presenting with no urinary symptoms suggestive of urinary tract infection at the time of urine collection but having a positive urine culture (colony count of $>10^{5} \mathrm{per} \mathrm{ml}$ of urine). The antibiotic sensitivity of the identified pathogens was studied.
\end{abstract}

Results: The commonest organism found was Coliforms $(n=79)$. The other organisms identified were Staphylococci $(n=10)$, Streptococci $(n=7)$ and Enterococci $(n=2)$. All the organisms were sensitive to Nitrofurantoin. However, Nitrofurantoin was used only in 57 women.

Conclusion: As all the organisms were sensitive to Nitrofurantoin, prescribing practices need to be changed to include Nitrofurantoin as the first line of therapy for asymptomatic bacteriuria of pregnancy.

\section{BACKGROUND}

The prevalence of asymptomatic bacteriuria in pregnancy is between $2 \%-10 \%$ and varies among different ethnicities and socio economic groups ${ }^{1}$. Asymptomatic bacteriuria in pregnancy, if left untreated, is associated with increased maternal and perinatal morbidity and mortality ${ }^{2,3}$. The main stay of screening for asymptomatic bacteriuria in pregnancy is mid-stream sample of urine (MSU) for

\footnotetext{
a. Registrar in Obstetrics \& Gynaecology, Colombo South Teaching Hospital, Colombo, Sri Lanka.

${ }^{b}$ Senior Registrar in Obstetrics \& Gynaecology, Colombo South Teaching Hospital, Colombo, Sri Lanka,

c Senior lecturer, Department of Obstetrics \& Gynaecology, Faculty of Medical Sciences, University of Sri Jayewardenepura, Nugegoda, Sri Lanka

Correspondence: Dr. Samarawickrama N G C $L M B B S$
}

E-mail: clslalithcls@gmail.com

Competing interests: The authors report no conflict of interest culture and antibiotic sensitivity testing (ABST) in cases of positive cultures ${ }^{4}$. Even with some limitations, it remains the best screening tool since it carries satisfactorily high sensitivity and specificity rates when compared to other suggested screening methods ${ }^{5}$. Even though the detection of asymptomatic bacteriuria in pregnancy is incorporated in to developed countries health care management protocols ${ }^{5}$, routine screening for asymptomatic bacteriuria is not practical in developing countries due to non-availability of the standard laboratories, financial constraints and lack of human resources. Under treatment as well as usage of unacceptable and inappropriate broad spectrum agents will give rise to unwanted out comes such as persistence or recurrence of the infection, emergence of strains of organisms which resistant to most of the commonly using antimicrobials $^{6,7}$. Methicillin Resistant Staphylococcus Aureus (MRSA) strains, Extended Spectrum of beta Lactamase (ESBL) producing strains are seen with increased incidence in urine cultures obtained which have positive relationship with antibiotic abuse ${ }^{8,9}$.
The liberal use of major broad spectrum antibiotics has increased in Sri Lanka, and unacceptably short courses of treatment with antibiotics has also become a common feature in managing patients especially at General Practitioner level ${ }^{10,11}$.

According to the national guidelines, Nitrofurantoin is recommended as the first line therapy for pregnant women with positive urine cultures depending on their antibiotic sensitivity patterns ${ }^{12}$. However due to various reasons (side effects of the drug, personal preferences, etc.), it has been observed that the usage of Nitrofurantoin is suboptimal.

The aim of this study was to study organisms causing asymptomatic bacteriuria in pregnancy, their antibiotic sensitivity patterns and the type of antibiotic for treating these women with asymptomatic bacteriuria in pregnancy.

\section{METHOD}

At the Colombo South Teaching Hospital (CSTH) a descriptive cross sectional study was carried out from June 2015 to April 2016 on 98 consecutive pregnant women between eight to 24 weeks of gestation, residing in Colombo district and presenting with no urinary symptoms suggestive of urinary tract infection at the time of urine collection, but having a positive urine culture (colony count of $>$ $10^{5}$ per ml of urine).

Participants who gave a history of substandard collection of urine sample for culture, those who had been treated for urinary tract infections or who had a history of recurrent urinary tract infections, those who had chronic renal disease due to any cause or any autoimmune disease were excluded from the study.

All the samples were assessed in the microbiology laboratory of the CSTH. Samples were cultured on Cystine Lactose Electrolyte Deficient (CLED) Agar medium and a colony count of more than $10^{5}$ per ml of urine was taken as significant bacteriuria. The antibiotic sensitivity was assessed in accordance with Clinical and 
Laboratory Standard Institute guidance, United State of America ${ }^{13}$. The urinary culture and antibiotic sensitivity reports were provided to the attending clinicians who managed these women. The type of antibiotic prescribed by the attending clinicians was recorded. Statistical analyses were carried out by using the Statistical Package for the Social Sciences version 18.0 (SPSS Inc, USA). Data analysis was performed using descriptive statistics and Chi square test. A p value of
$<0.05$ was considered to be of statistical significance.

\section{RESULTS}

The commonest organism found was Coliforms $(n=79)$. The other organisms identified were Staphylococci $(\mathrm{n}=10)$, Streptococci $(\mathrm{n}=7)$ and Enterococci $(n=2$.) The sensitivity pattern of each organism for all the antibiotics which were tested is presented in Table 1, and the pattern of antibiotics prescribed, is presented in Table 2. All the organisms were sensitive to Nitrofurantoin but it was prescribed for only 57 women.

\section{DISCUSSION}

Even though all the samples were sensitive to Nitrofurantoin, the usage of Nitrofurantoin as the first line therapy for asymptomatic bacteriuria in

\begin{tabular}{|c|c|c|c|c|c|}
\hline \multicolumn{2}{|c|}{ Antimicrobial type } & $\begin{array}{l}\text { Percentage } \\
\text { of women } \\
\text { with } \\
\text { Coliform } \\
\text { infection } \\
\text { sensitive to } \\
\text { antibiotic } \\
(n=79)\end{array}$ & $\begin{array}{l}\text { Percentage of } \\
\text { women with } \\
\text { Staphylococcu } \\
\text { s infection } \\
\text { sensitive to } \\
\text { antibiotic } \\
(n=10)\end{array}$ & $\begin{array}{l}\begin{array}{c}\text { Percentage } \\
\text { of women } \\
\text { with }\end{array} \\
\text { Streptococcu } \\
\text { s infection } \\
\text { sensitive to } \\
\text { antibiotic } \\
(n=7)\end{array}$ & $\begin{array}{c}\text { Percentage } \\
\text { of women } \\
\text { with } \\
\text { Enterococcu } \\
s \text { infection } \\
\text { sensitive to } \\
\text { antibiotic } \\
(n=2)\end{array}$ \\
\hline \multicolumn{2}{|l|}{ Nitrofurantoin } & 100 & 100 & 100 & 100 \\
\hline \multirow[t]{3}{*}{ Cephalosporin } & Cephalexin & 62 & $\begin{array}{l}\text { Sensitivity not } \\
\text { assessed }\end{array}$ & $\begin{array}{l}\text { Sensitivity } \\
\text { not assessed }\end{array}$ & 0 \\
\hline & Cefuroxime & 50 & 100 & 100 & 100 \\
\hline & Cefotaxime & 100 & 100 & 100 & 100 \\
\hline \multirow[t]{2}{*}{ Quinolone } & Ciprofloxacin & 60 & 100 & 100 & 100 \\
\hline & Norfloxacin & 60 & 100 & 100 & 100 \\
\hline \multicolumn{2}{|l|}{ Co Amoxiclav } & 50 & 100 & 100 & 100 \\
\hline \multicolumn{2}{|l|}{ Cotrimazole } & 87 & 100 & $\begin{array}{l}\text { Sensitivity } \\
\text { not assessed }\end{array}$ & $\mathrm{O}$ \\
\hline \multirow[t]{2}{*}{$\beta$ lactams } & Amoxicillin & 37 & 0 & 100 & 100 \\
\hline & Ampicillin & 37 & 0 & 100 & 100 \\
\hline \multirow{3}{*}{$\begin{array}{l}\text { Aminoglycoside } \\
\mathrm{s}\end{array}$} & Gentamycin & 100 & 100 & 100 & 100 \\
\hline & Amikacin & 100 & 100 & 100 & 100 \\
\hline & Netilmycin & 100 & 100 & 100 & 100 \\
\hline \multirow[t]{2}{*}{ Carbapenems } & Imipenem & 100 & 100 & 100 & 100 \\
\hline & Meropenem & 100 & 100 & 100 & 100 \\
\hline
\end{tabular}

Table 1 Sensitivity pattern of various organisms to the antibiotics 


\begin{tabular}{|c|c|c|c|c|c|}
\hline $\begin{array}{l}\text { Organism } \\
\text { Antibiotic } \\
\text { Prescribed }\end{array}$ & $\begin{array}{c}\text { Coliforms } \\
(\mathrm{n}=79)\end{array}$ & $\begin{array}{c}\text { Staphylococci } \\
(\mathrm{n}=10)\end{array}$ & $\begin{array}{l}\text { Streptococci } \\
\qquad(\mathrm{n}=7)\end{array}$ & $\begin{array}{c}\text { Enterococci } \\
\qquad(n=2)\end{array}$ & $\begin{array}{c}\text { Total No of } \\
\text { women } \\
\text { treated }\end{array}$ \\
\hline Nitrofurantoin & 47 & 6 & 2 & 2 & 57 \\
\hline Cefuroxime & 14 & & 2 & & 16 \\
\hline $\begin{array}{l}\text { Co } \\
\text { Amoxiclav }\end{array}$ & 7 & 2 & & & 9 \\
\hline Cephalexin & 5 & & 3 & & 8 \\
\hline Amoxicillin & 6 & 2 & & & 8 \\
\hline
\end{tabular}

Table 2 The prescription of antibiotics for women with asymptomatic bacteriuria in pregnancy according to the identified organism $(\mathbf{n}=98)$

pregnancy was sub optimal. There is no evidence of any risks to the foetus when Nitrofurantoin is used during pregnancy, including the first trimester ${ }^{14,15}$. National and international guidelines recommend its usage as the first line therapy in treating urinary tract infections in pregnancy including asymptomatic bacteriuria in pregnancy ${ }^{12,}{ }^{16}$. More importantly Nitrofurantoin is a comparatively cheaper drug when compared to Cefuroxime or $\mathrm{Co}$ Amoxiclav. When there is more than one antibiotic for which a particular organism is sensitive, then the antibiotic which is cheaper and with no major side effects or adverse effects should be administered to patients. Therefore Nitrofurantoin should clearly have been the antibiotic of choice which should have been prescribed for the patients in the current study. Furthermore the usage of Co Amoxiclav during the latter part of pregnancy for preterm prelabour rupture of membranes has been shown to be associated with some adverse perinatal outcomes ${ }^{17}$.

If nausea occurs with the use of Nitrofurantoin, it can be minimized by proper counseling of the patients, modifying intake techniques such as taking it after meals and combining with anti-emetics if necessary.
Currently, screening for asymptomatic bacteriuria in pregnancy is not routinely practiced in many obstetric units in Sri Lanka. Limited laboratory resources, which are already burdened with a heavy work load, would the obvious limiting factor for the lack of routine screening in the country. Routine screening is not cost effective if the prevalence of asymptomatic bacteriuria in pregnancy is less than $2 \%{ }^{18}$. Evidence suggests that the prevalence of asymptomatic bacteriuria in pregnancy in Sri Lanka is approximately $3.6 \%$, which is-comparable to global figures ${ }^{19}$, and therefore routine screening would be justified.

The current study is limited by the fact that it only covered a single unit for a one year period. Further multi center studies are required covering a wider geographic area, for a comprehensive understanding of the prevalence of asymptomatic bacteriuria in pregnancy and its antibiotic sensitivity pattern in Sri Lanka.

In conclusion, all the organisms were sensitive to Nitrofurantoin. Prescribing practices need to be changed to include Nitrofurantoin as the first line of therapy for asymptomatic bacteriuria of pregnancy.

\section{ACKNOWLEDGEMENT}

To Professor Malik Goonewardene, MBBS, MS (Obs \& Gyn), FSLCOG, FRCOG (UK) for his invaluable guidance in the preparation of this article.

\section{REFERENCES}

1. Smaill FM, Vazquez JC. Antibiotics for asymptomatic bacteriuria in pregnancy. Cochrane Database of Systematic Reviews 2015, Issue 8. Art. No.: CD000490. DOI: 10.1002/14651858.CD000490.pub3. [Accessed on 12 ${ }^{\text {th }}$ May 2016]

2. Kass EH. Pyelonephritis and bacteriuria, A major problem in preventive medicine. Ann Intern Med 1962;56:46-53.

3. Kass EH. Pregnancy, pyelonephritis and prematurity. Clin Obstet Gynecol 1970;13:239-54. doi:10.1097/00003081-19700600000003. [Accessed on $15^{\text {th }}$ May 2015] 
4. Rubin RH, Shapiro ED, Andriole VT, Davis RJ, Stamm WE. Evaluation of new anti-infective drugs for the treatment of urinary tract infection. Clin Infect Dis 1992; 15(Suppl 1):S216-27.

5. Smaill F, Vazquez JC. Antibiotics for asymptomatic bacteriuria in pregnancy. Cochrane Database of Systematic Reviews 2007, Issue 2. Art. No.: CD000490. DOI: 10.1002/14651858.CD000490.pub2. [Accessed on $15^{\text {th }}$ May 2015]

6. Huovinen P. Increase in rates of resistance to trimethoprim. Clin Infect Dis. 1997;24(Suppl. 1): S63-S66.

7. Henquell C, Chanal C, Sirot D, Labia R, Sirot J. Molecular characterization of nine different types of mutants among 107 inhibitor resistant TEM beta lactamase for clinical isolates of E. coli. Antimicrob Agents Chemother. 1995;39:427-430.

8. Stefano CM Picozzi, Stefano Casellato, Mattia Rossini, Gaia Paola, Milvana Tejada, Luca Carmignani. Extended spectrum beta lactamase positive Escherichia coli causing complicated upper urinary tract infection: Urologist should act on time; Urol Ann. 2014 Apr Jun; 6(2): 107-112.
9. Meher Rizvi, Fathima Khan, Indu Shukla, Abida Malik, Shaheen. Rising prevalence of antimicrobial resistance in urinary tract infections during pregnancy: Necessity for exploring newer treatment options. J Lab Physicians: 2011 Jul Dec; 3(2):98-103.

10. Ingeborg Björkman, Johanna Berg, Nina Viberg, Cecilia Stålsby Lundborg. Awareness of antibiotic resistance and antibiotic prescribing in UTI treatment: A qualitative study among primary care physicians in Sweden; Scand J Prim Health Care. 2013 Mar; 31(1): 50-55.

11. CN Wijekoon, KMMP Dassanayake, A Pathmeswaran. Antimicrobial susceptibility patterns and empirical prescribing practices in adult inpatients with urinary tract infection in a tertiary care hospital in Sri Lanka: is there a need for changing clinical practices?; Sri Lankan Journal of Infectious Diseases 2014 Vol. 4(1):921.

12. http://s lma.1k/wp-content/ uploads/2014/12/Guidelines-onthe-use-of-antimicrobial-agents.pdf [Accessed on 04 ${ }^{\text {th }}$ August 2016]

13. and laboratory standard institute. http: // www.clsi.org. [Accessed on 2015, May]
14. Sulfonamide, nitrofurantoin, and risk of birth defects. Committee Opinion No. 494. American College of Obstetricians and Gynecologists. Obstet Gynecol 2011;117:1484-5.

15. Goldberg O, Koren G, Landau D. Exposure of nitrofurantoin during the first trimester of pregnancy and the risk for major malformations; J Clin Pharmacol. 2013 Sep;53(9):991-5.

16. http:// www.Gloshospitals.nhs.uk [Accessed on 04 ${ }^{\text {th }}$ August 2016]

17. 17. Kenyon S, Taylor DJ, TarnowMordi WO; ORACLE Collaborative Group. ORACLE-antibiotics for preterm prelabour rupture of the membranes: short term and long term outcomes. Acta Paediatr Suppl. 2002;91(437):12-5.

18. McCormick T, Ashe RG, Kearney PM. Urinary tract infection in pregnancy. The Obstetrician \& Gynaecologist 2008;10: 156-162.

19. Perera Jennifer, Randeniya Cyril, Perera Piyumi, Gamhewage Nimesha, Jayalathaarachchi Renuka. Asymptomatic Bacteriuria in Pregnancy: Prevalence, Risk factors and Causative Organisms; Sri Lankan Journal of Infectious Diseases 2012 Vol.1(2); 42-46. [Accessed on 15 May 2015] 